\title{
TECHNOLOGY APPLICATION IN HEALTH INFORMATION MANAGEMENT IN OBAFEMI AWOLOWO UNIVERSITY TEACHING HOSPITALS COMPLEX (OAUTHC) ILE-IFE, OSUN STATE
}

\author{
Eunice Olayinka ADEPOJU $(\mathrm{PhD})^{\mathbf{a}^{*}}$, Jacob Kehinde OPELE ${ }^{\mathbf{b}}$ \\ eunice.adepoju@eksu.edu.ng \\ a. Department of Vocational and Technical Education, Faculty of Education, Ekiti State University, Ado Ekiti, Nigeria. \\ b. Department of Library and Information Science, Faculty of Education, Federal University, Oye- Ekiti, Nigeria
}

\begin{abstract}
This study focused on technology application in Health Information Management in Obafemi Awolowo University Hospitals Complex Ile-Ife. A simple random sampling technique was employed for the selection of respondents for the study. A total of Seventy eight (78) respondents across the department was randomly selected for the study. Descriptive statistics was employed in the analysis of data collected for the study. The reliability test of the instrument shows a $(\alpha=0.9$ for staff level of awareness of technology use in health information management practice), $(\alpha=0.8$ for areas of technology application in health information practice), and for ( $\alpha=0.9$ for barriers of technology application in health information practice).The findings showed the majority of the respondent had good knowledge /aware of technology use in health information practices and the need for its application in the day-to-day administration of the hospital activities. The finding shows areas of technology application include: coding and indexing of clinical diagnosis, maintenance and records keeping, information processing and decision making, reduction of medical cost. The findings showed that majority of the respondents (80.8\%) identified such barriers as militating technology used in health information management in OAUTHC. The study concluded that technology has the potential of enhancing job satisfaction of health information management professionals. Lastly the study recommended that other departments in the hospital should also embark on similar study so as to have an overview of the impact of technology application in other departments of the hospitals for a generalized assessment.
\end{abstract}

Published by IJRP.ORG. Selection and/or peer-review under responsibility of International Journal of Research Publications (IJRP.ORG)

Keywords: Technology, Application, Health, Information, Health Information, Management

\section{Background of the Study}

Health is a key common liberty as perceived in the Universal Declaration of Human Rights (UDHR, 1948). It is a fundamental segment of advancement, essential to a country's monetary development and interior steadiness. The control of Health Information Management (HIM) is a quickly developing field that joins the exercises of medication, management, money, information technology, and law. Throughout the long term, the job of health information management experts has been to gather, approve, code, keep up, and make open the health information that specialists, attendants, and other healthcare suppliers depend on to convey quality healthcare. (AHIMA, 2008)

Health Information Management experts have mastery in overseeing patient health information, controlling PC information frameworks, securing patient protection, and coding determinations and methodology for healthcare administrations gave to patients. Health information technology (HIT) experts center around the specialized side of overseeing patient health information. They are specialists in the arranging, execution, and support of the product and equipment frameworks that healthcare experts use to catch, oversee, and store health information. Today, new technology and guidelines are fundamentally changing the health information management practice. The change from paper to electronic health records (EHRs) is prodding the making of huge health information stores that have never existed in this way making the order a technology bases field of study.

Technology is the assortment of strategies, abilities, techniques and cycles utilized in the creation of merchandise or benefits or in the achievement of destinations, like logical examination. Technology can be the information on strategies, measures, and so on or it tends to be implanted in machines, PCs, gadgets and industrial facilities, which can be worked by people without point by point information on the functions of such things.

Health information technology (HIT) is being looked for as one of the vital components to smooth out the way toward giving healthcare to improve quality and tackle cost. The Health Information Technology for Economic and Clinical Health (an arrangement of the American Recovery and Reinvestment Act of 2009 (ARRA) characterizes 
health information technology as "equipment, programming, coordinated advancements or related licenses, protected innovation, redesigns, or bundled arrangements sold as administrations that are intended for or support the utilization by health care elements or patients for the electronic creation, upkeep, access, or trade of health information.

Health information technology is the reason for a more persistent focused and proof based medication with the continuous accessibility of great information. Consequently, regardless of the different understandings of the extent of health information technology all healthcare partners concur that it is the reason on which a 21 st-century healthcare framework. Health information technology (HIT) comprises of set of advances with an incredible redirection for sending and overseeing health care information for all partners' utilization. Partners of health information incorporate payer, suppliers, guarantors, and any remaining gatherings with a premium in health and health care. HIT is the utilization of PC as doctor advanced help, electronic health records, mechanized doctor request section framework by specialists, patients, clinics, labs, x-beam offices and any remaining partners. Health information technology is vital piece of continually changing climate of health care framework. With the utilization of HIT health related information can be imparted well and can be utilized in proof based dynamic cycle. (Wikipedia 2006).

Advantages of HIT incorporate lessen paper work in clinic climate which brings about diminishing clinical blunders, decline need for rehashing clinical trials which impacts in decreasing health care cost. Proof based practice assume a vital part in effective health information framework quality, result and effectiveness of health. Health care framework can be improved by having ideal and precise information for proof based choices at all levels. Proactive employments of information technology in health area engage buyers of health administrations as they can without much of a stretch access health information just as choice device and by utilization of HIT health experts can team up more effectively when distance is a central point. (Wikipedia 2006).

The nature of health care is eventually decided by the effect of explicit health administrations on the patient's health information. Improving quality includes distinguishing and utilizing health Services that, when appropriately executed, produce the best improvement in health status. The most immediate commitment that information technology can make to improve the nature of health care is to give the clinician better information about the patient and health issue close by and elective tests and medicines for that issue, ideally at the mark of care. This would empower clinicians to pick more powerful administrations all the more rapidly and assist them with maintaining a strategic distance from awful blunders. The most important technology use in health care include: electronic patient records, organized information section, progressed human-PC interface advances, compact PCs, mechanized catch of information from analytic and checking gear, social data sets with online question (catchphrase search and recovery), information based processing, and PC organizations.

\section{Statement of the Problem}

Health information management is not a new thought. Infact, it is a profession that runs parallel with the practice of medicine. Hitherto, the science and art of health information management in OAUTHC has been greatly influenced by manual or print technology which has contributed to its low level of acceptability and recognition. Thus, the current study seeks to investigate the level of technology application in OAUTHC practice and how this has contributed to effective health care delivery in the hospital. It is expected that the outcome of this study will contribute to existing literature and practice of health information management.

\section{Objectives of the Study}

The main focus of this study is to examine the significance of technology application in the management of health information practice. This was achieved by means of the following specific objectives which are set to:

1. examine the level of awareness of technology use in health information practice among staff of health information management department in OAUTHC

2. investigate areas of technology application in health information management practice

3. find out the barriers militating technology application in health information management in OAUTHC 


\section{Overview of Health Information Management Practices}

Health information management (HIM) envelops every one of the assignments, occupations, titles, and associations engaged with the organization of health information, including assortment, stockpiling, recovery, and revealing of that information. HIM experts play out the capacities that help these exercises and much of the time grow their training to the connected exercises, including the monetary and specialized activities of a health care professional or association. HIM experts may aid the turn of events and execution of electronic health records (EHRs), regulate the upkeep of those data sets, offer help administrations like patient enlistment, recover information for announcing and proceeding with patient consideration, and take an interest in the charging cycle.

Heath Information Management Practices has to do with paper-based handling just as electronic records preparing; Health information management rehearses includes guaranteeing the accompanying exercises.

Completeness: Fulfillment alludes to the assortment or recording of information in their altogether. An exhaustive actual assessment that precludes any notice of the state of the patient's records. A total record upholds the records of patient. To guarantee that information assortment and recording are opportune and complete, health care associations, for example, medical clinic and different suppliers of health care, should create and execute information quality control.

Control: There are numerous chances for mistakes to happen. Information passage mistakes may happen whether transcribed or electronically entered. The basic role of documentation is correspondence. For instance, the documentation imparts among guardians for proceeding with patient consideration just as to payers, to legitimize and validate the consideration gave, and to administrative or authorizing organizations to exhibit the nature of patient consideration. Assuming a person's penmanship can't be perused by another health proficient, it become extremely hard to speak with each other One way the information can be ensured so they are precise, convenient and complete is through the turn of events and execution of powers over the assortment, recording, and detailing of the information. Health Information Management Department assumes a part in the recognition and rectification of certain documentation errors.an unsigned advancement note was utilized to act as an illustration of inadequate information.

In a paper based climate, the HIM expert would need to acquire the record and read the entirety of the advancement notes in it to recognize the fragmented note. In an electronic record climate, preventive control cautions, like clamors and verbal prompts, can be incorporated into the program to support the validation of the note at the time the note is initially recorded and furthermore on ensuing admittance to the record. As an analyst control, an exemption report can recognize fragmented notes in both paper based and electronic record conditions, the remedial control comprises of making the doctor aware of the oversight and allowing that person the chance to finish the note.

Correction of Errors: The revision of mistakes is a significant thought in persistent record keeping since nothing that is recorded ought to be erased. Revisions should be made so the blunder can be viewed as plainly as the adjusted information. In a paper based record, blunders are revised by drawing a line through the incorrect information and composing the right information close to it. It is significant not to darken the first section on the grounds that doing so may prompt the insight that somebody endeavored to conceal a mix-up. The amendment should be dated, coordinated, and validated. Also, revision of blunders can't comprise of annihilating whole archives or pages of a record. The entirety of the mistaken reports or pages should be plainly marked as off base, verified, planned and dated, and kept with the right segments of the record.

In electronic records, blunders can be rectified in a few different ways relying upon the kind of mistake and the information that are being changed. For instance, assume that a patient conceded to an office had been treated there previously. A record of the past visit exists. The patient enrollment expert ganders at the past record and finds that the patient has moved. The location and phone number are presently mistaken. Thusly the patient enrollment agent 
may erase the old information and supplant it in the patient's record with the new information. In doing as such, the product ought to be customized to make an authentic record of the patient's past addresses. Then again, a doctor gaining an adjustment to a headway note should make an addendum to the record, distinguishing the mistake and entering the new note. In the two cases, a review trail ought to be made to demonstrate that the adjustment was made..

Quantitative Analysis: Another significant investigator control that happens in the HIM division is quantitative examination. Quantitative investigation is the way toward inspecting a health record to guarantee that the record is finished by association arrangements and methodology for a total clinical record.

Record Completion: Once the missing components, or insufficiencies, are distinguished, the people in question are then needed to finish the record. The helpfulness of requiring clinical staff to verify records after release is to some degree dubious in light of the fact that the absence of confirmation has no clinical importance for patient consideration. For instance, if a doctor neglected to sign the advancement note of a patient who has effectively been released, what conceivable effect could the expansion of the mark have on the patient 30 days after the fact? Any control work that would have been influenced by the doctor's mark has been lost. A little advantage might be acquired if the passage is subsequently addressed. These contentions, obviously, are not important as long as licensure and authorizing offices are as yet auditing post release records for consistence with such norms.

Deficiency System: Once the patient's record has been explored and missing components have been recognized, the restorative control strategy is started. The party in question that is, the person who was answerable for setting up the report or marking the note or report is told and requested to finish the record. The most well-known inadequacies that exist in inpatient records are unlucky deficiencies of a release synopsis, a usable report, a conventional discussion report, and marks. This cycle of recording, revealing, and following missing components in a record is known as the insufficiency framework or, in certain offices, the deficient framework. This framework applies to review examination. Simultaneous examination isn't by and large recorded and followed in light of the fact that the clinician is relied upon to see the banner, regardless of whether it is physically embedded or PC created, the following time the person in question audits the record.

Coding: Coding is the portrayal of conclusions and systems as alphanumerical qualities to catch them in the information base. Conclusion and system codes are utilized for instance to convey information about patients among suppliers, to follow and investigate infections, for repayment, and to encourage research. Normalizing snippets of information in this manner permits correspondence of unmistakable findings, methodology, and different sorts of clinical information with a superior power over information quality. In spite of the fact that product can surely assess and coordinate with the two names for a similar illness, an incorrect spelling of either term could prompt disarray.

Retrieval: It is suitable to make reference to here that in a paper climate, stockpiling is an exceptionally basic capacity in the office. The capacity and maintenance of health records, just as the capacity to recover those records effectively, are customarily the obligation of HIM experts. When the records are finished and documented, the requirement for recovery depends on various components. On the off chance that nobody could at any point need to take a gander at the record again after the patient has returned home, it shouldn't be coordinated, investigated, or put away. As recently referenced, notwithstanding, the health record is the business record that upholds treatment and installment and is a basic specialized instrument; it will be assessed commonly after the patient leaves the emergency clinic. The capacity of recovering the health record and giving it or parts of it, to individu-als who need it is ordinarily called arrival of information (ROI). It is critical that HIM experts comprehend who is approved to get a record, who is approved to get a duplicate of a record, and how to set up a record for audit. 
Storage and Retention: During transformation to an electronic record, strategies and techniques should be set up to characterize what establishes the legitimate health record. In electronic framework this definition ought to be determined by medical clinic strategy. In the mixture record in which a paper outline is produced and afterward examined into the electronic record, approaches should indicate what will befall the paper record. The strategy should address whether the paper record will be obliterated or kept up in offsite capacity. Maintenance issues should be tended to in the approach. How long will the paper record be kept up away before it is obliterated? Will Computer based information be accessible on the web or chronicled over.

Identification of Records To Process: ID of released patients: what records should be handled? This can be cultivated by assessing a rundown of the patients who have been released. The releases register or release list. As patients are released from the medical clinic, their status is refreshed in the PC framework. The released date and time are entered. This information passage might be performed by nursing or enrollment staff since they are the people destined to know precisely when the patient has left. Bed control is informed, either physically or electronically, that the patient's bed is empty. Housekeeping is advised that the room should be cleaned. Each of the three undertakings (release, notice, and cleaning) should happen to concede another patient that bed. In the event that the patient leaves yet the release date isn't recorded and bed control not advised, the quantity of patients in the emergency clinic (registration) is inaccurate and the release list is feeling the loss of a patient. This nitty gritty comprehension of the release cycle and how it is acted in one's clinic empowers clients of the release register to recognize and address blunders.

Assembly: is the arrangement of methods by which a paper records is redesigned after release and arranged for additional preparing. The degree to which a record is redesigned shifts among medical clinics. The need to redesign the record emerges from the contrasts between the request for the segments and reports of the record utilized in post release preparing. Also, the documentation is by and large coordinated inside segments backward sequential request, with the latest date on top. Redesign of a paper record is done physically by HIM staff individuals, who are regularly called constructing agents. A few executives question the expense adequacy of this capacity. Why take a coordinated record and redesign it? The appropriate response is that the necessities of the clients on the patient unit, while the patient is being dealt with, are unique in relation to the requirements of the clients after the patient has been released. (Health information technology third version, Topic health information management measure by NadiniaDavis.MelissaLacour page 140 chap 5)

\section{Health Information Technology (HIT)}

Health Information Technology is applied to health and health care. It upholds health information management across modernized frameworks and the safe trade of health information between buyers, suppliers, payers, and quality screens. In view of a regularly refered to 2008 report on a little arrangement of studies led at four locales that give mobile consideration three U.S. clinical focuses and one in the Netherlands the utilization of Electronic Health Records (EHRs) was seen as the most encouraging apparatus for improving the general quality, security and productivity of the health conveyance framework. (From Wikipedia, the free reference book 2006 report by the office for healthcare examination and quality)

The application of information preparing including both PC equipment and programming that manages the capacity, recovery, sharing, and utilization of health care information, information, and information for correspondence and dynamic. Technology is an expansive idea that manages an animal varieties' use and information on apparatuses and artworks, and what it means for an animal categories' capacity to control and adjust to its current circumstance. Nonetheless, a severe definition is subtle; "technology" can allude to material objects of utilization to humankind, like machines, equipment or utensils, yet can likewise incorporate more extensive subjects, including frameworks, strategies for association, and methods.

What's more, health information frameworks have advanced through a few unique advances. Haux (2006) portrays frameworks that cycle information and gives information and information in healthcare conditions as health information frameworks. Medical clinic information frameworks are only an occurrence of health information 
frameworks, in which a clinic is the healthcare climate just as healthcare foundation. The point of health information frameworks is to add to an excellent, proficient patient consideration. Some of phrasings identified with HIS are as per the following. Health Informatics is simply the field that worries with the intellectual, information handling, and correspondence assignments of clinical practice, schooling, and exploration including the information science and technology that upholds those undertakings. Health informatics devices incorporate PCs just as clinical rules, formal clinical wordings, and information and correspondence frameworks. At the end of the day, it accentuation is on clinical and biomedical applications with added probability of the incorporating clinical parts either among themselves or to more authoritative sort health information frameworks. (Conrick, 2006).

Likewise, Health information technology is the application of information handling including both PC equipment and programming that manages the capacity, recovery, sharing, and utilization of health care information, information, and information for correspondence and dynamic (Goldschmidt, 2005). Another significant wording in HIS is Electronic Medical Records (EMR), it dwells at the focal point of any health information frameworks. EMR is a clinical record in a computerized design, though electronic health record (EHR) alludes to an individual patient's clinical record in an advanced arrangement. EHR frameworks organize the capacity and recovery of individual records with the guide of PCs, which are generally gotten to on a PC, regularly through a PC organization. One of the significant patterns is the move towards a widespread electronic patient record (EPR). EPR is characterized as electronically put away health information around one individual interestingly recognized by an identifier.

Basically EPR technology involves catching, putting away, recovering, communicating, and controlling patient explicit, healthcare related information independently and extensively, including clinical, authoritative, and personal information (Protti et al., 2009). Perhaps the most fascinating parts of HIS is the manner by which to deal with the connection between healthcare suppliers and patients. Encouraging great connection with client (patient) will hold them and pull in them to become faithful clients, make more noteworthy shared agreement, trust, and fulfillment. Also, a decent relationship will empower patient's association in dynamic (Richard and Ronald, 2008). A decent connection will cultivate viable correspondence which is regularly connected with improved actual health, more viable ongoing infection management, and better health related personal satisfaction (Arora, 2003). Overseeing relationship should persistently create and develop. A decent relationship is a unique one that the association become alarm to and mindful of evolving needs. Thusly, when healthcare associations oversee well, patients will need to return, since dependability and trust are fabricated. They will realize that on the off chance that they present a trouble, the associations will resolve expertly. (Conrick, M. (2006)

As of not long ago, ICT items accessible for healthcare suppliers were generally intended for enormous associations and were exorbitant. Ongoing advances in technology have made ICT applications more accessible to essential consideration doctors in more modest practices. Most emergency clinics in Kenya have not yet mechanized the different health care arrangement offices. The center and utilitarian level medical attendant administrators don't have a PC in their workplaces or at their work areas (International Journal of Applied Research 2015).The utilization of ICT advances advancement and improves administrations in any association. It gets changes the present business climate. Authoritative, ecological and social elements remain against the great and saw will of the utilization of ICTs. At the point when health care suppliers are not PC educated, using the office would be an issue. ICT information is a principal imperative for effectiveness in healthcare arrangement in the current society. Information Communication and Technology (ICT) information empowers health care suppliers to upgrade patient consideration conveyance, just as the training and wellbeing of care. Health care suppliers everywhere on the world are required to stay up with ICT improvements to help them settle on educated choices in regards to patient consideration and management. Client's mentality toward the entire marvel of ICT influences his/her eagerness to utilize PCs and subsequently an association's capacity to advance toward a paperless framework. It's imperative to build up the current demeanor of health care suppliers to decide how computerization will be accomplished.

Realizing the ability levels of the health care suppliers would set up the competency levels and henceforth structure a reason for building up the ideal abilities Health care suppliers at various levels impact medical clinic system and plan nursing exercises to give a serious climate. For instance, regulatory assignments (like rounding out structures and handling charging demands) address a critical part of healthcare costs. Health Information Technology could smooth out these undertakings and altogether decline costs, just as decrease individual visits to specialists for those living in distant territories, this regularly implies doing without a whole day's pay. ICT in healthcare can empower far off discussion, finding and treatment through telemedicine. Information Communication Technology (ICT) insurgency carried openings and difficulties to non-industrial nations in their endeavors to reinforce the Health Management Information Systems (HMIS). 
For HIT, technology addresses PCs and interchanges credits that can be arranged to assemble frameworks for moving health information. Two normal parts of health information technology are electronic clinical records and modernized doctor request passage. (Chaudhry, B. Wang, J., and Wu, S. et al., (2006).Wiki/health IT)

Electronic Health Record (EHR), or Electronic Medical Record (EMR), alludes to the organized assortment of patient and populace electronically-put away health information in an advanced arrangement. These records can be shared across various health care settings. Records are shared through network-associated, undertaking wide information frameworks or other information organizations and trades. EHRs may incorporate a scope of information, including socioeconomics, clinical history, prescription and sensitivities, vaccination status, lab test results, radiology pictures, indispensable signs, individual measurements like age and weight, and charging information. EHR frameworks are intended to store information precisely and to catch the condition of a patient across time. It wipes out the need to find a patient's past paper clinical records and helps with guaranteeing information is precise and readable. It can diminish hazard of information replication as there is just a single modifiable record, which implies the document is almost certain state-of-the-art, and diminishes hazard of lost administrative work.

Because of the advanced information being accessible and in a solitary record, EMR's are more compelling while removing clinical information for the assessment of potential patterns and long haul changes in a patient. Populace based investigations of clinical records may likewise be encouraged by the boundless reception of EHR's and EMR's. (Wiki/Health IT). Information Communication Technologies (ICT, for example, electronic health records, e-recommending, choice emotionally supportive networks, electronic management of ongoing infection and bar coding of medications and natural items have been appeared to diminish health care expenses and clinical mistakes. Electronic recommending has been appeared to lessen blunders and improve consistence with oversaw care models. Information Communication and Technology (ICT) information empowers health care suppliers to upgrade patient consideration conveyance, just as the training and wellbeing of care. Realizing the ability levels of the health care suppliers would set up the competency levels and henceforth structure a reason for building up the ideal abilities.

Computerized physician order entry (CPOE) is the cycle of a clinical expert entering drug orders or other doctor guidelines electronically rather than on paper graphs. An essential advantage of CPOE is that it can help decrease blunders identified with helpless penmanship or record of medicine orders. CPOE frameworks are intended to emulate the work process of the paper outline. The time and cash it takes to introduce a CPOE framework are two generally refered to disadvantages of the technology. CPOE selection has been delayed because of supplier obstruction, generally as a result of the interruption to existing consideration settings and the expense of execution, which incorporates CPOE preparing. The expense of a CPOE execution can be in the large numbers, and yearly upkeep can add many thousands to that absolute. A CPOE execution can be carried out to various offices continuously, now and again requiring a long time to finish. The Healthcare Information and Management Systems Society's online CPOE asset records six stages required for an ideal CPOE execution: starting, arranging, executing, observing and controlling, changing to tasks, and improvement and upkeep after the establishment is finished. POE frameworks are regularly utilized pair with e-recommending frameworks, which ready doctors and clinicians to a specific patient's medication sensitivities and current meds. CPOE frameworks were in the past much of the time sold as independent frameworks. Numerous electronic health record items currently come furnished with CPOE modules that permit getting doctors enter patient information electronically into text boxes and drop-down menus, instead of penmanship notes. (Gunter, Tracy D, Terry and Nicolas P (2005).

Health Technology: The term health technology covers a scope of strategies used to advance health administrations, forestall infections and treat them suitably. With the utilization of health technology transient consideration (restoration) and long haul care which incorporate medications, gadgets and methods can be improved. There are not many instances of health information technology utilized in various health arrangements which remember the computerization of clinical records for emergency clinics and centers, utilization of web for archive conveyance, information trade and correspondence, improvement of e-cards for patient distinguishing proof, advancement of electronic planning framework to give arrangements, clinic labs and clinic confirmation assessment and mechanized 
convention for analysis and giving treatment support. HIT framework gives improved dynamic and fitting utilization of indicative research facility tests and restorative specialists. (CPOE: Coming to medical clinic close to you: J Scott Litton .doctor practice walk 2012)

\section{ICT Utilization in Health Information Practices}

Oketunji (2001) shared the view about the world being a "worldwide town' with the progressive assembly of the internet and correspondence advances. This is the sign that the world has been revolutionalize with the appearance of these advances. The central issue at that point is, with this unrest, how have the less evolved countries profited themselves the chance of the new patterns to redesign their social ability for public turn of events? In his own accommodation, Adedeji (2001) communicates the view that "the arising worldwide pattern in information technology and the accompanying effect on the arrangement of information administrations combined with a convincing requirement for a proceeding with instruction on the best in class, make it more basic for libraries and information focuses to persistently evaluate its significance inside a powerful climate as our own". This shows that for libraries and information focuses to be socially pertinent in the innovative age, they must be more unique and reject traditionalism. Oketunji (200 1) Stresses the capacity of the web as giving an approach to analysts to have better admittance to one another and to instruments that encourage their explores. He keeps up that web could give significantly more to instructive organizations and offers the capacity to lead distant classes; gives admittance to a huge assortment of information, permits admittance to far off libraries, and establishes a climate where understudies can have imaginative agreeable learning encounters. Along these lines, the chance exists for it to revolutionalize training; one could go to a college actually while classes are taken distantly at colleges around the country. Specialist could investigate all the more intimately with foundations turning out to be individuals from the web local area (Salman, 2003). Oketunji (2000) citing Marghalani composed that information technology as a term incorporates the thought of the application of the ICT for the dealing with, age, stockpiling, handling, recovery, and spread of information. This definition infers that it is limited to framework - subordinate upon a miniature electronic based mix of registering and media transmission innovations.

A comprehension of information technology could come in the types of three divisions, specifically; as an empowering influence of development, as a help for information handling assignments and as a "colapser" of existence. Then again, the pattern in correspondence technology today is information portability. This has to do with the new correspondence advances like remote, cell phone, etc, which don't need for customary telephone or correspondence frameworks.

There are other correspondence advancements that could encourage social reconciliation, for example, fax-machine, email, and phone. Comprehend that the nature, quality or amount of information undeniably, decides the degree at which correspondence happens. (ICT availability and use)

Health information management (HIM) is a quickly developing field that joins the controls of medication, management, money, information technology, and law. Verifiably, the job of HIM experts has been to gather, approve, code, keep up, and make open the health information that specialists, attendants, and other healthcare suppliers depend on to convey quality healthcare.

HIM experts have aptitude in overseeing patient health information, regulating PC information frameworks, ensuring patient protection, and coding analyses and techniques for healthcare administrations gave to patients. Health information technology (HIT) experts center around the specialized side of overseeing patient health information. They are specialists in the arranging, execution, and support of the product and equipment frameworks that healthcare experts use to catch, oversee, and store health information.

As of late, new technology and guidelines are changing the health information field and these jobs significantly. The change from paper to electronic health records (EHRs) is prodding the production of immense health information storehouses that have never existed. In coming years, the test to healthcare suppliers will be to mine and investigate these information to deliver noteworthy health information that can be utilized to improve patient consideration at decreased expenses. This new spotlight on electronic information management and examination will significantly change the jobs and instruction necessities of HIM and HIT experts, making some conventional jobs old while 
bringing about totally new openings especially occupations zeroed in on technology organization and information investigation which are starting to arise today.

The boundless utilization of Information and Communication Technologies (ICT) has pervaded practically all parts of life including the healthcare area. HIS was acquainted with completely use particularly the Internet in giving better healthcare. Health information frameworks are every now and again alludes to the connection between individuals, cycle and technology to help activities, management in conveying fundamental information to improve the nature of healthcare administrations. Like some other enterprises, the idea of healthcare industry has changed over the long haul from a moderately steady industry to a dynamic.

\section{Obstructions to the Adoption of Technology in Health Information Management}

As demonstrated in the writing, normal obstructions to technology application in health information management incorporates:

ICT Infrastructure: Most of immature nations don't have needed mechanical foundation to set up public health information framework subsequently can't advance HIT in private and public clinics. Reshaping framework of existing health framework is vital. Coming up next is portrayal of infrastructural obstructions: Poor or Inadequate Infrastructure Most agricultural nations don't have satisfactory required foundation like PC equipment, programming, wired and remote correspondence channels, Internet, and talented expert human asset. The accessibility and activity of these segments of ICT Infrastructure are essential for foundation and advancement of HIT in immature nations. Solid framework is needed for the solid health information framework to improve existing health framework by arranging and presenting new health care intercessions which brings about accomplishing better health objective. The fundamental troubles or boundaries in utilizing information innovations incorporates lacking framework, deficient admittance to the equipment, in insufficient or helpless assets assignment. By dispensing with these obstructions populace health status can be improved in non-industrial nations. (Mugdha, 2007)

Lacking assets portion: For execution and utilization of the health technology in the agricultural nations, Provision of Computer Hardware and Software. HIT requires particular programming and equipment to improve general health by settling on proof based choices. Regularly these product and equipment instruments are expensive and require adequate preparing for legitimate activity. (Mugdha, 2007)

Helpless Internet Availability: Poor web accessibility is a crucial framework boundary. Health care experts have helpless admittance to continuous information and the accessible information isn't as per the neighborhood circumstance. This accessible information can't be utilized for proof based choices. Without having a legitimate neighborhood and web office between hierarchical and intra-authoritative correspondence is unimaginable. This is a spine for any information framework. (Mugdha, 2007)

Absence of Professional Human Resource Workforce: A modernized information framework requires gifted faculty for its compelling activity. Preparing is one of the angles for utilization of any new technology. Insufficiency of gifted labor force can be overwhelmed by giving suitable preparing in the necessary zone. An appropriate preparing module in developing engineering of a solid data set ought to be accessible. Assuming it isn't executed, results or results acquired by such sort of data sets gives unauthentic outcomes which can nor be utilized for dynamic cycle nor for proof based practice. Preparing requires cost just as time. (Mugdha, 2007)

Cost and Time: Major issue in getting sorted out workshops and trainings for foundation and execution of HIT in immature nations is monetary and time requirement. Change of any framework is a troublesome undertaking and can't finish in brief timeframe period. Obstructions like absence of talented labor force, foundation, and cost alongside different impacts like introductory decline of profitability because of change with new mechanical climate and framework itself force, solid cutoff points to the presentation and adaption of new health advancements. It requires a long time for change interaction to finish. (Worldwide Journal of Advanced Computer Science and Applications, 2011)

Social and Cultural: Digital separation and e-availability are significant social and social hindrances in foundation and utilization of health information framework. These boundaries incorporate absence of partner's revenue, less inspiration, tension to adjust and utilize new technology. Health care staff are hard to persuade for utilization of new health innovations. As they are more alright with their traditional methodology and routine practice so it is confounded to change health information framework from paper based to advanced organization. The social boundaries are maybe the most huge. From the viewpoint of the specialist, the most often referenced incorporate that clinicians see health IT (especially EHR) as tedious and they are too occupied to even consider managing it; they don't see how might this benefit them; they dread that it will depersonalize healthcare and all the more explicitly, will meddle with their compatibility with their patient; they see it as a danger to patient protection and classification 
and as an expected device for 'Elder sibling' obstruction in their training. The issue of security likewise comprises an impediment from the point of view of the patient.(Mugdha, 2007)

Specialized and proficient boundaries: The serious issues experienced in this classification incorporate an absence of synchronization between the framework and clinical work process; purchasers(doctors) who are inadequately set up to settle on fitting choices about what to buy; clinicians going about as experts to framework engineers who are truly not qualified because of their absence of preparing in biomedical informatics; the absence of an expert labor force in clinical informatics fit for driving the execution; and the absence of a key authoritative interaction to build up the responsibility of the entirety of the stakeholders.(Mugdha, 2007)

Instructive Professional: schooling in health informatics is seriously overlooked and missing in educational program of clinical organizations for students. In spite of the fact that module of instruction identified with IT use in research is remembered for postgraduate educational program however it is the need of great importance to remember this region for clinical expert training at graduate level. Change of our current paper based health framework into automated information framework is unimaginable without giving the essential IT information to health experts. (Mugdha, 2007)

Authoritative: Organizations and individuals assume an extremely basic part in executing and change of an information framework. Above all else there are no recorded examinations accessible with respect to level and utilize, benefits, cost, hazard investigation and different parts of health technology in health area of immature nations and on the off chance that they are accessible for the non-industrial nations they are not all around imparted. Furthermore, individuals at higher positions and posts, whose requirements of announcing are satisfactorily being cooked by the current framework, don't support HIT as they feel that the work of new technology is wastage of both the cash and time. Medical clinics should address the worry of doctors since, supposing that by utilizing HIT their expert duties become troublesome they won't ever uphold its utilization.

\section{Theories of ICT System Implementation and Adoption}

The theory of Technology Acceptance Model by Davis (1989) in the MIS Quarterly with thousands of studies testing Technology Acceptance Model in the information system area, Technology Acceptance Model is increasingly applied as a fitting theory for the information management context. In the Technology Acceptance Model, there are two determinants including perceived ease of use and perceived usefulness. Perceived usefulness is the degree to which an individual believes that using a particular information system or information technology would enhance his or her job or life performance.

Perceived ease of use is the degree to which a person believes that using a particular information system or information technology would be free of effort. Perceived ease of use and perceived usefulness positively affect the attitudes toward an information system. Since its introduction by Davis (1989) and Davis et al. (1989), Technology Acceptance Model has been widely used for predicting the acceptance, adoption, and use of information technologies.

The theoretical foundation of this conceptual model comes from combining earlier researches in technology acceptance (Davis, 1989), Davis, Bagozzi and Warshaw 1989) which consists of some factors as shown below:

Facilitating conditions: this is an objective factor in the environment in which observers agree that it makes an act easy to accomplish.

Perceived usefulness: this is defined as the degree to which a person believes that using a particular system would enhance his or her job performance.

Perceived ease of use: it is defined as "the degree to which a person believes that using a particular system would be free of effort.

This theory is relevant to this study because it identifies the process of changing from paperless to a new system which has been discussed. The ability of the staff to embrace the application of technology.

\section{Methodology}

This chapter is discussed under the following sub sections, research design, study population, sample size and sampling techniques, instrumentation, validity and reliability of instruments, data collection procedure and source of data, and method of data analysis. The study employed descriptive survey design, which involves using a self-designed questionnaire in collecting primary data from the respondents. The study population for this studywere members of staff of Health Information Management Department Obafemi Awolowo University Teaching Hospitals 
Complex, (OAUTHC) Ile-Ife. The populations consist of all the 84staff in the department comprising both professional and para professionals. Eighty-four (84) staff of health information management department were studied using complete enumeration (census) technique. The instrument used to collect data was semi structured questionnaire. The questionnaire was divided into four sub-sections namely (A, B, C and D). Section (A) focused onsocio demographic characteristics of the respondent such as. Age, Marital status, Sex, educational background etc. Section (B) was design to examine the awareness level of technology use in health information management practice in OAUTHC. Section (C) examined the areas of technology application in Health information practice. While Section (D) examined the barriers of technology application in health information management practice in OAUTHC.

Validity refers to the extent to which conclusion or a measurement is well founded and corresponds accurately to the real world. It is the degree to which a test measure what is intended to measure. It is the extent to which the measurement reflects the true state of affairs. Hence content validity was ensured with the contributions of the supervisor.Reliability tells us how closer the measurements are to each other when repeated it has to do with the quality of measurement, scope and relevance to the study. All the necessary corrections were done on the instrument before final administration, through vetting and scrutinizing by the supervisor. Cronbach's alpha was used to measure the reliability of items in the questionnaire and $\infty=0.6$ and above was considered reliable. The below shows the results. The questionnaire was distributed to the participants in their various units. A self-administered questionnaire method was adopted in the course of this study and this approach was easy and appropriate due to the study objectives, study design, time available for the study, The respondents filled the questionnaire carefully and correctly before retrieval for the analysis. The collection of the questionnaire was done at the agreed time by both parties.

The set of data collected for the study were analysed using Statistical Package for Social Sciences (SPSS) version 20. The results were presented using frequency counts and percentage distribution, mean and standard deviation.All ethical issues surrounding data collection analysis and reporting was observed in the course of study.

\section{Discussion of Findings}

As seen in the this study, the respondents' age group ranges between 20 and above 50 years which shows that the study was carried out among staff who are in their active occupation age. The studies revealed further that majority $(44.0 \%)$ of the respondents were female compare to male $(34.0 \%)$. The study also indicates the number of single to married respondents, professionals and para-professionals staff.

As regards respondents highest educational qualification. The study revealed that highest percent of the respondents were university graduates $30.0 \%$ followed by those with ordinary national diploma (OND) (27.0\%) and those who had higher national diploma (HND) while (17.0\%) had a bachelor's degree in science (B.Sc) while only few had senior school certificate examination (SSCE), postgraduate diploma (PGD) and Master of science (Msc). This implies that the participants were literate.

The study revealed further that majority of the respondents $(67.9 \%)$ were extremely aware of technology application in health information management practices in OAUTHC. These further revealed that majority of the respondents (69.2\%) have heard about technology use and related facilities with good knowledge of their uses. This also corroborates the study of health information technology is the application of information processing involving both computer hardware and software that deals with the storage, retrieval, sharing and use of health care information data and knowledge for communication and decision making (Goldschmidt, 2005).

This also supports the study conducted on ICT utilization in health information management system which is often associated with improved physical health, more effective chronic disease management and better health related quality of life (Arora 2003).

The study identified among other barriers of technology application; poor internet availability, inadequate funding, ICT illiteracy, cost of training, slowness of the internet, installation and maintenance, unstable electricity supply and lack of consistent technical support to mention a few. This support the study conducted on technology application in health information department by Conrick, (2006). 
Above all, the respondent level of awareness about technology application in health information was very high and when it comes to the areas of technology application the findings of this revealed that technology uses in health information cut across every sections and units of the department. In fact, technology uses in the library, coding and indexing section as well as statistical collation were among the top priority areas of its application.

\section{Tables Discussion}

Table 4.1 provides some useful information on the hospital units, age, sex, marital status, educational background, job titles/cadre and years of working experience. As shown in the table, majority $(92.1 \%)$ were from Health Information Management Department Ife hospital unit. Most of the respondent were female (56.4\%), while males (43.6\%). Most of the respondents were married (55.1\%) while (43.6\%) were singles, the highest percentage of the respondents had OND35.9\%, followed by (34.6\%) HND, 21.8\% had BSc, and others had (3.8\%), while (1.3\%) and (1.3\%) had PGD and MSc. The table also revealed that, $(52.6 \%)$ had spent $1-5$ years, followed by $38.5 \%$ that had spent 6-10years, and 9.0\%had spent 11-15years in service. The table also shows $42.3 \%$ were Health Records Officer I, is followed by $15.4 \%$ Health Records Officer II,(2.6\%) others were Chief Health Records Officer, and (11.5\%) Health Records Technician while (28.2\%) were Health Records clerks respectively.

As shown in table 4.2,(67.9\%) of the respondents extremely aware that technology made it possible to quickly find and distribute health information, this was followed by (65.4\%) technology aids effective statistical collation. this agrees with earlier studies such as (Richard \& Ronald 2008).Also (61.5\%) extremely aware that technology used minimizes time spent looking and pulling of files. (61.5\%) extremely aware that technology aids statistical presentation and reporting and a total of (61.5\%) respondents are also extremely aware that technology supports hospital and physicians practices. While ( 60.3\%) are extremely aware that technology safe hospital cost of paper stationeries, Also (60.3\%) of the respondents extremely aware that technology used help to minimize misfiling and mislaying of patients records, a total of (56.4\%) are aware that technology helps in the registration of patients, while (51.3\%) of the respondents are aware that technology improves communication among health care providers according to earlier study, as one of the most interesting aspects of health information system is how to manage the relationship between healthcare providers and patients (Protti et.al. 2009). and also (43.6\%) technology enhances access to patient's clinical information. Haux (2006) describes systems that process data and provides information and knowledge in healthcare environment and its aim is to contribute to a high quality, efficient patient care respectively.

Table 4.3 showed that $(69.2 \%)$ of respondent strongly agreed that technology helps in organization of day to day activities of the department while (64.1\%) strongly agrees technology helps in maintenance of records, (57.7\%) strongly agreed that technology is useful in coding and indexing, (57.8\%) others strongly agrees that technology enhances patient care delivery, while (53.8\%) agreed that technology supports information processing, decision making and record keeping rank low, $(47.4 \%)$ of respondent strongly agreed that technology to reduces health care and medical cost. This corroborates the study of (Conrick 2006) who reported that technology enhances health information system.

As shown in table 4.4(80.8\%) agreed that poor internet availability hinders the use of technology in HIM, (71.8\%) identified inadequate funding as hindering the use of technology in HIM. (67.9\%) identified unstable electricity supply, other barriers include (62.8\%) ICT illiteracy, (55.1\%) lack of consistent technical support. (53.8\%) slowness of the internet $(51.3 \%)$ cost of training, and (47.4\%) cost of internet installation and maintenance. This implies that more still need to be done to achieve complete technology application in health information management practices. 
Table 1: Test of reliability and validity in support of the results

\begin{tabular}{|l|c|c|c|}
\hline \multicolumn{1}{|c|}{ Survey items } & \multicolumn{2}{|c|}{ Reliability Statistics } \\
\hline \multicolumn{1}{|c|}{$\begin{array}{c}\text { Cronbach's } \\
\text { Alpha }\end{array}$} & $\begin{array}{c}\text { Cronbach's Alpha Based on } \\
\text { Standardized Items }\end{array}$ & No of Items \\
information management practice & 0.934 & 0.934 & 10 \\
\hline $\begin{array}{l}\text { Areas of technology application in health information } \\
\text { practice }\end{array}$ & 0.800 & 0.811 & 6 \\
\hline $\begin{array}{l}\text { Barriers of technology application in health information } \\
\text { practice }\end{array}$ & 0.865 & 0.869 & 8 \\
\hline Overall score & 0.833 & 0.783 & 24 \\
\hline
\end{tabular}

Table 2: Respondents Socio demographic characteristics

\begin{tabular}{|c|c|c|c|}
\hline SurveyItems & Classification & Frequency & Percentage \\
\hline \multirow[t]{4}{*}{ Unit } & IHU, Ile-Ife & 48 & 61.5 \\
\hline & Wesley Ilesha & 23 & 29.5 \\
\hline & Eleyele & 7 & 9.0 \\
\hline & Total & 78 & 100.0 \\
\hline \multirow[t]{4}{*}{ Age range } & $20-30$ & 45 & 57.7 \\
\hline & $31-40$ & 23 & 29.5 \\
\hline & $41-50$ & 10 & 12.8 \\
\hline & Total & 78 & 100.0 \\
\hline \multirow[t]{3}{*}{ Sex } & Male & 34 & 43.6 \\
\hline & Female & 44 & 56.4 \\
\hline & Total & 78 & 100.0 \\
\hline \multirow[t]{4}{*}{ Marital Status } & Single & 34 & 43.6 \\
\hline & Married & 43 & 55.1 \\
\hline & Widower & 1 & 1.3 \\
\hline & Total & 78 & 100.0 \\
\hline \multirow[t]{7}{*}{$\begin{array}{ll}\text { Highest } & \text { Educational } \\
\text { Qualification } & \\
\end{array}$} & SSCE & 3 & 3.8 \\
\hline & NCE/OND & 30 & 35.9 \\
\hline & HND & 27 & 34.6 \\
\hline & Bsc & 17 & 21.8 \\
\hline & PGD & 1 & 1.3 \\
\hline & Msc & 1 & 1.3 \\
\hline & Total & 80 & 100.0 \\
\hline \multirow[t]{4}{*}{ Cadre } & Health Record Officer 1 & 33 & 42.3 \\
\hline & Health Record Officer 2 & 12 & 15.4 \\
\hline & Chief Health Record Officer ' & 2 & 2.6 \\
\hline & Heath Record technician & 9 & 11.5 \\
\hline
\end{tabular}




\begin{tabular}{|l|l|c|c|}
\hline & Health Record Clerk & 22 & 28.2 \\
\hline & Total & $\mathbf{7 8}$ & $\mathbf{1 0 0 . 0}$ \\
\hline Working experience & $1-5$ & 41 & 52.6 \\
\hline & $6-10$ & 30 & 38.5 \\
\hline & $11-15$ & 7 & 9.0 \\
\hline & Total & $\mathbf{7 8}$ & $\mathbf{1 0 0 . 0}$ \\
\hline
\end{tabular}

Table 3: Showing level of Technology use in Health Information Management Practices

\begin{tabular}{|l|l|l|l|l|l|l|l|c|}
\hline S/N & Survey Statements & $\begin{array}{l}\text { Not at } \\
\text { all aware }\end{array}$ & $\begin{array}{l}\text { Slightly } \\
\text { aware }\end{array}$ & $\begin{array}{l}\text { Somewhat } \\
\text { aware }\end{array}$ & $\begin{array}{c}\text { Moderately } \\
\text { aware }\end{array}$ & $\begin{array}{c}\text { Extremely } \\
\text { aware }\end{array}$ & Mean & Std dev \\
\hline 1 & $\begin{array}{l}\text { technology has made it } \\
\text { possible to quickly find and } \\
\text { distribute health } \\
\text { information }\end{array}$ & $1(1.3)$ & $1(1.3)$ & $9(11.5)$ & $14(17.9)$ & $53(67.9)$ & & \\
\hline 2 & $\begin{array}{l}\text { technology aids effective } \\
\text { statistical collation }\end{array}$ & $4(5.1)$ & $4(5.1)$ & $5(6.4)$ & $14(17.9)$ & $51(65.4)$ & 4.33 & 1.136 \\
\hline 3 & $\begin{array}{l}\text { the use of technology } \\
\text { eliminate time currently } \\
\text { spent looking for and } \\
\text { pulling of records }\end{array}$ & $2(2.6)$ & $5(6.4)$ & $6(7.7)$ & $17(21.8)$ & $48(61.5)$ & & \\
\hline 4 & $\begin{array}{l}\text { technology aids statistical } \\
\text { presentation and reporting }\end{array}$ & $1(1.3)$ & $10(12.8)$ & $2(2.6)$ & $17(21.8)$ & $48(61.5)$ & 4.29 & 1.094 \\
\hline 5 & $\begin{array}{l}\text { technology safe hospital } \\
\text { cost of paper stationary }\end{array}$ & $2(2.6)$ & $6(7.7)$ & $3(3.8)$ & $20(25.6)$ & $47(60.3)$ & 4.33 & 1.040 \\
\hline 6 & $\begin{array}{l}\text { Misfiling and mislaying of } \\
\text { patients' records will be } \\
\text { laid to rest through } \\
\text { technology application }\end{array}$ & - & $6(7.7)$ & $6(7.7)$ & $19(24.4)$ & $47(60.3)$ & & 1.040 \\
\hline 7 & $\begin{array}{l}\text { technology helps in the } \\
\text { registration of patients }\end{array}$ & $2(2.6)$ & $4(5.1)$ & $6(7.7)$ & $22(28.2)$ & $44(56.4)$ & 4.87 & 1.427 \\
\hline 8 & $\begin{array}{l}\text { technology improves } \\
\text { communication among } \\
\text { health care providers }\end{array}$ & $4(5.1)$ & $1(1.3)$ & $7(9.0)$ & $26(33.3)$ & $40(51.3)$ & 4.24 & 1.034 \\
\hline 9 & $\begin{array}{l}\text { technology enhances access } \\
\text { to patient's clinical } \\
\text { information }\end{array}$ & $4(5.1)$ & $10(12.8)$ & $5(6.4)$ & $25(32.1)$ & $34(43.6)$ & 3.96 & 1.221 \\
\hline 10 & $\begin{array}{l}\text { technology supports } \\
\text { hospital and physicians } \\
\text { practice }\end{array}$ & $5(6.4)$ & $5(6.4)$ & $3(3.8)$ & $17(21.8)$ & $48(61.5)$ & 4.26 & 1.200 \\
\hline
\end{tabular}


Table 4: showing Areas of Technology Application in Health Information Practice

\begin{tabular}{|c|l|c|c|c|c|c|c|}
\hline S/N & \multicolumn{1}{|c|}{ Survey Statements } & $\begin{array}{c}\text { Strongly } \\
\text { agree }\end{array}$ & Agree & $\begin{array}{l}\text { Strongly } \\
\text { disagree }\end{array}$ & Disagree & Mean & $\begin{array}{c}\text { Std } \\
\text { dev }\end{array}$ \\
\hline 11 & $\begin{array}{l}\text { Technology helps in day to day activities of } \\
\text { health information services }\end{array}$ & $54(69.2)$ & $24(30.8)$ & - & - & 1.31 & .465 \\
\hline 12 & $\begin{array}{l}\text { Technology helps in maintenance and record } \\
\text { keeping of patients }\end{array}$ & $50(64.1)$ & $28(35.9)$ & - & - & 1.36 & .483 \\
\hline 13 & $\begin{array}{l}\text { Technology helps in coding and indexing of } \\
\text { clinical diagnosis }\end{array}$ & $45(57.7)$ & $30(38.5)$ & - & $3(3.8)$ & 1.50 & .698 \\
\hline 14 & Technology enhances patients care delivery & $45(57.7)$ & $28(35.9)$ & $3(3.8)$ & $2(2.6)$ & 1.51 & .698 \\
\hline 15 & $\begin{array}{l}\text { Technology supports information processing, } \\
\text { decision making and record keeping }\end{array}$ & $42(53.8)$ & $33(42.3)$ & $3(3.8)$ & - & 1.50 & .575 \\
\hline 16 & $\begin{array}{l}\text { Technology to reduce health care and medical } \\
\text { cost }\end{array}$ & $37(47.4)$ & $30(38.5)$ & $7(9.0)$ & $4(5.1)$ & 1.72 & .836 \\
\hline
\end{tabular}

Table 5: Showing Barriers of Technology Application in Health Information Management Practices

\begin{tabular}{|l|l|c|c|c|c|c|c|}
\hline S/N & \multicolumn{1}{|c|}{ Barriers } & $\begin{array}{c}\text { Extreme } \\
\text { barrier }\end{array}$ & $\begin{array}{c}\text { Moderate } \\
\text { barrier }\end{array}$ & $\begin{array}{c}\text { Some } \\
\text { barrier }\end{array}$ & $\begin{array}{c}\text { Not a } \\
\text { barrier }\end{array}$ & Mean & $\begin{array}{c}\text { Std } \\
\text { dev }\end{array}$ \\
\hline 17 & Poor internet availability & $63(80.8)$ & $9(11.5)$ & $5(6.4)$ & $1(1.3)$ & 3.72 & .643 \\
\hline 18 & inadequate funding & $56(71.8)$ & $17(21.8)$ & $5(6.4)$ & - & 3.65 & .599 \\
\hline 19 & unstable electricity supply & $53(67.9)$ & $18(23.1)$ & $6(7.7)$ & $1(1.3)$ & 3.58 & .694 \\
\hline 20 & ICT illiteracy & $49(62.8)$ & $19(24.4)$ & $8(10.3)$ & $2(2.6)$ & 3.47 & .785 \\
\hline 21 & lack of consistent technical support & $43(55.1)$ & $22(28.2)$ & $9(11.5)$ & $4(5.1)$ & 3.33 & .878 \\
\hline 22 & slowness of the internet & $42(53.8)$ & $25(32.1)$ & $9(11.5)$ & $2(2.6)$ & 3.37 & .791 \\
\hline 23 & cost of training & $40(51.3)$ & $23(29.5)$ & $14(17.9)$ & $1(1.3)$ & 3.31 & .811 \\
\hline 24 & $\begin{array}{l}\text { cost of internet installation and } \\
\text { maintenance }\end{array}$ & $37(47.4)$ & $30(38.5)$ & $10(12.8)$ & $1(1.3)$ & 3.32 & .747 \\
\hline
\end{tabular}

\section{Summary of Findings}

This research examined the Technology Application in Health Information Management practices in Obafemi Awolowo University Teaching Hospitals Complex. A total of 78 respondents across the different units of the departmentof health information management were selected for the study, using census technique and these includes professional and Para-professional in department of Health Information Management, Obafemi Awolowo University Teaching Hospital Complex (OAUTHC) Ile-Ife Osun State. Data analysis was done by means of descriptive statistics.Such as frequency counts and percentage distribution. The findings revealed that most of the respondents were highly knowledgeable on the application of technology in health information management practices. The finding further revealed that technology help in the workflow of the job specification of every member of staff of health information management department.

It was observed from the findings that $80.8 \%$ of respondents identified poor internet availability as one of the barriers to technology application in Health Information Management while $71.8 \%$ identified inadequate funding and $67.9 \%$ also identified unstable electricity supply.

\section{Conclusion}

From the findings of the study, it is evidence that technology application in health information management department cannot be overemphasized in this technology age, the study showed that information and communication 
technology (ICT) is required for information processing in particular the use of electronic health records system and computer software to convert, store, process, transmit and retrieve information. The study revealed that technology has the potential of enhancing job satisfaction of health information management professionals.

\section{Recommendations}

The following recommendations were suggested based on the findings of this study:

1 The staff in the department should be trained on how to make better use of their ICT infrastructures particularly electronic health records system and software system.

2 Health information management department staff should be informed on the importance of technology use and its economic benefits in their day to day activities.

3 Application of ICT technology in the day-to-day administration of the hospital management should be encouraged in all the department of the hospital. Not only health information management department for sustainable development of Nigeria health sector.

4 Other departments in the hospital should also embark on similar study so as to have an overview of the impact of technology application in the other department of the hospital for a generalized assessment.

\section{References}

Adedeji, Okanlawon O. (2001) Automation in the 21st Century: The Role of Cataloguers: Automation of Cataloguing Practices in Nigerian Libraries Proceedings of Selectedpapers Presented at the Workshop of the Nigeria Library Association Cat. \& Class, Indexing Section 1995 to 2000.p. 6.

AHIMA. (December 17, 2008) Health Information Management: Professional

Definition.Accessedathttp://www.ahima.org/infocenter/definitions/him professional definition.p

American Recovery and Reinvestment Act of 2009 (ARRA)

Chaudhry, B. Wang, J., \& Wu, S. et al., (2006). Systematic review: Impact of health information technology on quality, efficiency, and costs of medical care, Annals of Internal Medicine, 144(10), 742-752.

Conrick, M. (2006). Health informatics: Transforming healthcare with technology. Thomson Social Science Press. [10] E-Health Ontario, 2009, ePrescribing, viewed 1 March 2011, http://www.ehealthontario.on.ca/programs/ePrescribing.as

CPOE: Coming to hospital near you: J Scott Litton .physician practice march 2012

Davis, F. D. (1989) "Perceived Usefulness, Perceived Ease of Use, and User Acceptance ofDavis, F. D., R. P. Bagozzi and P. R. Warshaw (1989) "User Acceptance of Computer

Goldschmidt, P.G. (2005). HIT and MIS: Implications of health information technology and medical information systems. Communications of the ACM, 48(10), 69-74.

Gunter, Tracy D; Terry, Nicolas P (2005). "The Emergence of National Electronic Health Record Architectures in the United States and Australia: Models, Costs, and Questions". Journal of Medical Internet Research 7.

Health information technology third edition, Topic health information management process by Nadinia A. Davis .Melissa Lacour MBA, RHIA, CHDA,CCS,FAHIMA, Melissa Lacour .page 140 chap 5

Information Technology", MIS Quarterly (13)3, pp. 319-342.Technology: A Comparison of Two Theoretical Models”, Management Science (35) $8, \mathrm{pp}$

International Journal of Advanced Computer Science and Applications, 2011982-1003.

Mugdha R Oak, A review on barriers to implementing health informatics in developing countries, Journal of Health Informatics in developing countries, vol 1, No. 1, 2007

Oketunji, Ibadapo (2000) Application of Information Technologies in Nigerian Information Science Ed Mugdha R Oak, A review on barriers to implementing health informatics in developing countries, Journal of Health Informatics in developing countries, vol 1, No. 1, 2007

Protti, D., Johansen, I. and Perez-Torres, F. (2009) 'Comparing the application of health informationtechnology in primary care in Denmark and Andalucía, Spain', International Journal of MedicalInformatics, Vol. 78, pp. 270-283.

Robert Wood Johnson Foundation (2008). Health Information Technology in the United States: The Information Base for Progress. 
Richard, L.S., and Ronald M.E. 2008. Lessons from Theory \& Research on Clinician-Patient Communication In: Karen G., Barbara K.R, K.Viswanth (eds.) "Health Behaviour and Health Education; Theory, Research, and Practice" 4th edition, (11) p 236-269 JOSSEYBASS

Salman, A. A. (2002) Appraisal of Career Opportunities for Library and InformationManagers in Less Developed Countries (LDCs). A Paper Presented at the 2002 Annual Conference of NLA Kwara State Chapter, p. 7.

2006 report by the Agency for Healthcare Research and Quality broad and consistent utilization of HIT, International Journal of Applied Research 20151 (11) 1025-1029 